\title{
New records of brittle stars from French Guiana: Ophiactis savignyi and the alien species Ophiothela mirabilis (Echinodermata: Ophiuroidea)_ERRATUM
}

\author{
GORDON HENDLER AND SOPHIE J. BRUGNEAUX
}

doi: 10.1017/S1755267213000845, Published by Cambridge University Press, 29 October 2013 (online).

In this paper the final paragraph of the Discussion was printed incorrectly. It should read:

Note added in proof: Recently O. mirabilis has also been discovered off Tobago. On 6-13 July 2013, Keri Wilk observed abundant individuals living on gorgonians at depths of 12-18 m, near SCUBA diving sites at Store Bay, Goat Island, and Little Tobago. The ophiuroids are indistinguishable from O. mirabilis found in French Guiana, St Vincent, and Brazil, based on Wilk's excellent underwater macro photographs. They may have been introduced to Tobago via coastal currents, or by marine vessels, as O. mirabilis occurred within 15-30 km of the Port of Scarborough. The latest distributional records underscore that O. mirabilis now is widespread in Atlantic waters. Moreover, the Tobagan and Vincentian populations seem well positioned to disseminate westward via the Caribbean Current and/or human mediated transport. We express our appreciation to Keri and Les Wilk for sharing information and photographs.

REFERENCE

Hendler G. and Brugneaux S.J. (2013) New records of brittle stars from French Guiana: Ophiactis savignyi and the alien species Ophiothela mirabilis (Echinodermata: Ophiuroidea). Marine Biodiversity Records 6 (e113), 1-5. doi: 10.1017/S1755267213000845. 